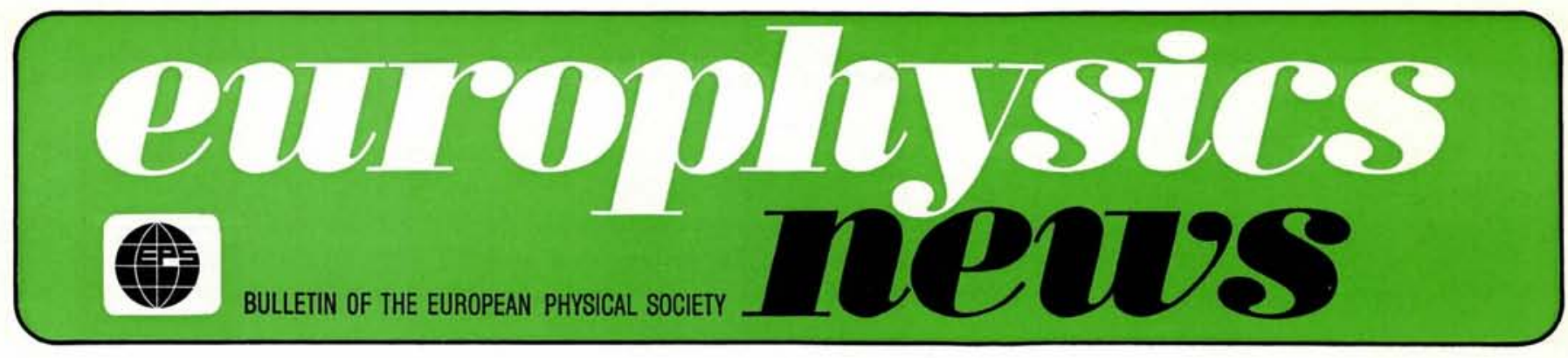

\section{Viewpoint}

\section{Physics data}

The European founder of experimental physics in the thirteenth century, Robert Grosseteste, first set forth a methodology for physics. As A.C. Crombie wrote in Robert Grosseteste and the origins of experimental science: $1100-1700$ :

With this methodological revolution, there appeared in the Latin West a clear understanding of the relation between theory and observation on which the modern conception and practice of scientific research and explanation are based, a clear set of procedures for dealing with physical problems.'

In those intervening seven hundred years, the explanatory powers of physical theory have been extended to give its tremendous insight into natural phenomena. However, in order that physics can continue to fulfill its other task of correlating observational data, these data have to be reliable and based upon agreed criteria and procedures of recording, evaluation and compilation. Formulation and co-ordination of the criteria and procedures on an international scale are the tasks of CODATA - featured in this issue. American physicists have responded to the challenge of physics data by co-operating in publication of the Journal of Physical and Chemical Reference Data.

Physicists in Europe, where such a high proportion of physics data is generated, might wish to pay due attention to the real problems of data reliability that CODATA have identified.

\section{Contents}

Viewpoint . . . . . . . 1

Plans of EPS Divisions . . 1 CODATA . . . . . . . 4

Copernicus and physics. . 6 Astronomy and Astrophysics 7 Society News Meetings

\title{
Plans of EPS Divisions
}

In order to give an accurate impression of the extensive activity within the Specialized Divisions of the European Physical Society, this article has brought together contributions from each Division. Clearly, EPS Divisions are fulfilling their function of providing European focuses for physics and physicists within their specialized fields in a lively and varied fashion.

\section{Atomic Physics}

The Atomic Physics Division was established by EPS Council in March 1971. Nearly 250 physicists are members of this new Division. The elected Board comprises $H$. van Regemorier (Chairman), T. Skalinski, A. Steudel. G. zu Putlitz, K.F. Smith, A.H. Gabrie!. The Chairmen and Secretaries of the 3 Sections are ex officio members of the Board: Chairman of the Section on Electronic and Atomic Collisions is J. Hasted; Chairman of the Section on Molecular Physics is I. Kovacs ; Chairman of the Section (EGAS) on Atomic Spectroscopy is B. Edlen.

Most of the scientific activities will be organized by the Sections. There will be some large conferences like the 5 th Annual Conference on Atomic Spectroscopy which will be held in Lund (Sweden) from 10-13 July 1974, and the 11th European Congress on Molecular Spectroscopy which will be organized in Tallin (USSR) from 28 May to 1 June 1973 (Information from T. Saluvere, Academy of Sciences, Lenini Pulestee 10, 200001 Tallin, USSR).

Some conferences will concern more specialized topics related to the field of one Section, like the Europhysics Study Conference on 'Atomic and Molecular Physics of Ionized Gases' (Versailles, France, 3-5 April 1973) and the conference on 'Impact Ionization' (Englefield Green, UK, 2326 July 1973). But the Atomic Physics Division is planning to organize and stimulate conferences on specialized topics which are at the boundaries of neighbouring domains, like the Europhysics Study Conference on 'Spectral Line Broadening and Related Topics' which will take place in Paris, 2-6 July 1973.

Information can be obtained and suggestions can be made by writing to the present Chairman: $H$. van Regemorter, Observatoire de Meudon, F - 92 Meudon, (France).

\section{H. van Regemorter, Chairman}

\section{Condensed Matter}

The Condensed Matter Division is now by far the largest Division in EPS. Consequently, Council agreed that the Condensed Matter Division should be conceived as a Confederation of Sections each of which is largely autonomous, although they collaborate closely with the Board of the Division. Such a scheme allowed the previous Low Temperature Division to become a Section of the Condensed Matter Division.

The Sections of the Condensed Matter Division are now :

- Liquids and Amorphous Materials

- Low Temperature Physics

- Magnetism

- Metals

- Macromolecular Physics

- Semi-conductors and Insulators.

The relationship of the European High Pressure Research Group to the Condensed Matter Division is not yet fixed definitely. 


\section{Europhysics Conferences}

The following Europhysics Conferences have been organized by Sections of the Condensed Matter Division for 1973 :

Magnetism Soft Magnetic Materials I (Torino, Italy, 3-5 September)

Metals Metal Surfaces (Gothenburg, Sweden, 13-15 August)

Magnetism Rare Earth Metals and Metals (Elsinore, Denmark, August-September)

\section{Elections}

According to the statutes proposed for the Condensed Matter Division, each of the Sections elects a Committee of six members. The electors are the Individual Ordinary Members of EPS who have registered in the Section. The elections will probably take place early in 1973.

Individual Ordinary Members of EPS, whether already members of the Division or newly joined, will be invited by the Main Secretariat to indicate with which Section(s) they wish to be associated.

\section{A. Guinier, Chairman}

\section{High Energy and Particle Physics (HEPP)}

Under the Chairmanship of $A$. Zichichi, a joint meeting between the old and the newly-elected Boards of the HEPP Division took place, in Wiesbaden, on the occasion of the 2nd EPS General Conference. The people present were: G. Bernardini, G. Charpak, R.H. Dalitz, M. Froissart and W. Paul. A. Zichichi first reviewed the activities which had been carried out by the Division and indicated their present status, as follows :

1. An EPS Conference on 'Meson Resonances and Related Electromagnetic Phenomena' had been organized by the HEPP Division and held at Bologna in April 1971. The Conference Proceedings were now available.

2. A drive for new Individual Ordinary Members for EPS had been carried out in all countries possible, and this had improved the membership situation very greatly. However, the membership of the HEPP Division still comprises a small fraction of the high-energy physicists in Europe, so that continued efforts would still be needed.

3. Discussions had been held concerning further Conferences or Dis- cussion Meetings, which might be organized by the Division. No suggestions had been returned by the members of the Division despite a request from the Interim Board.

4. The present activity in international collaboration among European physicists seems to be very satisfactory owing to the existence of CERN. However, the problem of co-ordination of the future developments at the national laboratories in different countries, and of their relationships with CERN, has recently gained great interest, but action has yet to be taken.

Regarding this last point of the discussion, we learned that ECFA (European Committee on Future Accelerators), an independent organization grouping high-energy physicists of CERN countries, has decided to investigate the optimization problems in the three-way relationship among CERN, large national laboratories and smaller university groups, in the light of the recent drop in expansion rate of high-energy physics which appears to have affected the whole community. Collaboration between ECFA and the HEPP Division on that matter will certainly be welcome and useful.

After his report, A. Zichichi invited M. Froissart to outline the state of plans for the next European Conference on High Energy Physics, which would be sponsored jointly by EPS and the French Physical Society. This Conference will be held at Aix during 6-12 September 1973, and would have an attendance of about 600 physicists. The emphasis would be on Very-HighEnergy Physics. The Joint Board decided that the following schedule of attendance fees should be proposed to the Advisory Committee for this Conference: Individual Ordinary Members of EPS Fr. fr. 150.-, Members of National Physical Societies Fr. fr. 200.-, and non-Members Fr. fr. 250.-.

The Joint Board decided that it should consider organizing the next Conferences in this series, starting in 1975 (perhaps in Italy), as true HEPP Divisional Conferences.

The need to attempt to assess the financial means and the number of physicists (and perhaps of specialized technicians) available to High-Energy Physics in Europe in the next few years was discussed in the light of the many changes occurring quite rapidly both within the profession and in the political background. It was decided that further attention should be given to this question in future meetings.
The transfer of power from the Interim Board to the newly-elected Board was carried out.

The Chairman and Secretary of the new Board were elected, in that order, with the following results :

Chairman : M. Froissart

Secretary: G. Charpak

The other members of the new Board are: A. Baldin, G. Bernardini, J. Hamilton, H. Lipkin and W. Paul.

A. Zichichi, Interim Board Chairman, and $M$. Froissart, Chairman

\section{Nuclear physics}

In the field of nuclear physics, the Europhysics Conference Scheme is dominated by the large Munich conference (27 August - 1 September 1973). It will be organized by the two local universities under sponsorship of, among others, IUPAP and EPS. The ensuing large concentration of nuclear physicists in Europe will give occasion to the organization of several minor and specialized satellite conferences. An EPS Divisional Conference, however seems superfluous in 1973.

Future Divisional conferences might very well profit from the existing experience in organizing large national or bilateral conferences. The nuclear physics sections of several national societies regularly have general meetings of a high standard. By yearly expanding the scope of one or two of these meetings, they might efficiently serve as Europhysics Divisional Conferences.

In connection with the internationalisation of the national conferences, a European equivalent of the Bulletin of the American Physical Society would be very helpful. Therefore the ad-interim Board has suggested that EPS investigate the possibility of publishing such a European bulletin. It would stimulate the contacts between European physicists on a working level, an essential and desirable complement to organizational contacts.

International 'summer'schools in nuclear physics are being organized on local or national levels. The schools in Poland (Rudziska and Zakopane) and in Romania (Predeal) appear to have become highly appreciated yearly events.

As soon as the problem has been solved of getting a set of Divisional rules approved by Council, the adinterim board will dissolve itself to make way for a board properly (s) elected in a traditional, democratic manner.

\section{C. van der Leun, Secretary}




\section{Physics in Astronomy}

Various proposals for future Divisional activities were discussed at the First Meeting of the newly elected Board of the Division, held in Wiesbaden on 5 October 1972. It was agreed that the Division would recommend EPS sponsorship of scientific meetings which were, in general, complementary to, rather than competitive with, those being organized by other bodies. These meetings would be primarily of a specialized nature, on topics where co-operation between physicists and astronomers would appear especially valuable. The Division would also wish to co-operate with other bodies in the organization of larger and more general meetings (in particular, close involvement of the Division in the organization of future European Assemblies of the IAU was envisaged).

Specific topics suggested for future specialized conferences during 197374 included stellar evolution, solidstate astrophysics, star formation, and astronomical instrumentation. No firm dates are yet fixed for many of these meetings, it being especially important to avoid any clash with the extensive IAU activities in 1973.

The Board recommended sponsorship of the 'Summer Session on Theoretical Astrophysics' in Trieste from 1 July - 15 September 1973. There will be a study group on stellar evolution organized by $\mathrm{F}$. Pacini in Frascati during the summer of 1973.

M.J. Rees, Europhysics News Correspondent.

\section{Plasma Physics \\ Organization}

At the Europhysics Divisional Conference in Grenoble, a Board meeting was held on 23 August 1972. A new Divisional Board was elected and comprised the following members:

P. Vandenplas (Chairman); B. Lehnert (Vice-Chairman); E. Weibel (Treasurer) ; C.M. Braams ; T. Consoli; J.L. Delcroix (Representative in Summer Schools and Student Exchange Advisory Committee) ; F. Engelmann (Correspondent to Europhysics News); B.B. Kadomtsev; J. Kistemaker (Representative in Applied Physics and Physics in Industry Advisory Committee) ; D. Pfirsch (Representative in Conferences Advisory Committee); P. Reynolds (Representative in Publications Advisory Committee); R.Z. Sagdeev.

\section{EPS Plasma Physics Journal}

The creation of a European plasma physics journal of high reputation and status has been under consideration. The following possibilities have been discussed :

(a) Distribution of the working papers of Europhysics Divisional meetings as arranged by EPS ;

(b) Creation of a special plasma physics letters journal ;

(c) Conversion of one of the largest European journals in plasma physics into the main journal of plasma physics in Europe, with the same status and volume as, for example, The Physics of Fluids in the United States.

\section{Meetings}

The Sixth European Conference on Controlled Fusion and Plasma Physics (the next Europhysics Divisional Conference) will be held in Moscow from 30 July - 3 August 1973. Organizer of the Conference is $M$. Rabinovich, P.N. Lebedev Institute, Akademija NAUK, Moscow. Organizing bodies are the Atomic Energy Committee and the Akademija NAUK, USSR. Invitations to the Conference have been sent out by the Organizing Committee in Moscow. An International Congress on Waves and Instabilities in Plasmas is being organized by F. Cap in Innsbruck, Austria, from 2-7 April 1973. This Congress is a Europhysics Topical Conference in the programme of the Plasma Physics Division.

There are plans for two further conferences on controlled fusion and plasma physics in 1975, and one conference on cosmic plasmas in 1974 .

\section{Schools}

P. Vandenplas and J.L. Delcroix have been successful in arranging a permanent summer school, every second year, on 'Plasma Physics' at Les Houches, France. The Board considered that one permanent school is sufficient, and that some flexibility should be left in the schools programme of the Division.

\section{B. Lehnert, Vice-Chairman}

\section{Quantum Electronics}

The Quantum Electronics Division of the European Physical Society was founded by decision of the Council of EPS on 14 July 1969. As a result of elections last year, the Board now consists of 11 elected and one co-opted member. The elected members are: S. Akhmanov (USSR), F.T. Arecchi (Italy), D.J. Bradley (UK), J. Ernest (France), W. Kaiser (Fed. Rep. of Germany), G. Mayer (France), K.P. Meyer (Switzerland), S.A. Ramsden (UK) (Chairman), F.P. Schafer (Fed. Rep. of Germany), O. Svelto
(Italy), and Q.H.F. Vrehen (Netherlands) (Secretary). The co-opted member is J.C. Viénot (France), representing the field of coherent optics.

The major activities of the Division for 1973 will be as follows :

(a) Divisional Conference. The 1973 meeting will be held in Italy under the Directorship of $O$. Svelto. The topic will be 'Lasers and Spectroscopy'. The meeting will take place in the last week of August either in Milan or in a resort area around Milan. More detailed information about the Conference will be given when available.

(b) Summer School. The Division has promoted (since 1972) a yearly International School of Quantum Electronics within the 'Ettore Majorana' Centre for Scientific Culture (Erice, Sicily). The school is directed by F.T. Arecchi and D. Roess. The course of this year will be on the topic 'Laser Frontiers - High Power and Short Wavelength' and will be held from 2-16 June 1973 with P. Caldirola and S.A. Ramsden as Course Organizers.

(c) A European 'Who's who?' in Quantum Electronics is in preparation. This booklet will list people according to the laboratories to which they belong, rather than in purely alphabetical order by names.

O. Svelto, Europhysics News Correspondent.

18-30 June 1973

INTERNATIONAL ADVANCED STUDY INSTITUTE

on

\section{Elementary excitations in solids, molecules and atoms}

\section{UNIVERSITY OF ANTWERP BELGIUM}

Scientific Director :

Prof. Dr. J. DEVREESE

PHYSICS DEPARTMENT

UNIVERSITY OF ANTWERP

Fort VI straat

B - 2610 WILRIJK (Belgium)

Sponsor: NATO 